Vladimir D. Mihajlović

Univerzitet u Novom Sadu

Filozofski fakultet

Odsek za istoriju

v.mihajlovicc@gmail.com
Originalni naučni rad

primljeno: 9. maj 2011

prihvaćeno: 1. oktobar 2011

\title{
INHUMACIJA U RANORIMSKOM PERIODU NA CENTRALNOM BALKANU: ODRAZ DRUŠTVENO-IDEOLOŠKIH PROMENA? *
}

Sažetak: U radu se preispituju dosadašnji zaključci o pojavi inhumacije u periodu ranog Rimskog carstva na području centralnog Balkana i predlaže se novi način sagledavanja ove pojave. Polazeći od pretpostavke da su pogrebne prakse vezane za socijalnu strukturu zajednice u kojoj se vrše, nudi se mogućnost da je pojava inhumacije bila povezana sa restrukturiranjem lokalnih zajednica koje se dogodilo u procesu uključivanja u šire rimske socijalne mreže i tokove.

Ključne reči: inhumacija, ranorimski period, centralni Balkan, arheologija pogreba.

Jedan od najinteresantnijih fenomena u arheologiji rimskog carskog perioda je promena tretmana tela umrlih, odnosno napuštanje incineracije i prihvatanje inhumacije. I pored mnogih pokušaja arheologa da osvetle razloge koji su stajali u pozadini ove promene, nedvosmisleni i konačni zaključci nisu doneti, i pitanje je da li će ikada biti. Kako je ova pojava imala opšti karakter na teritoriji zapadne polovine Carstva, područje centralnog Balkana nije ostalo mimo širih tokova. U ovom radu se preispituju dosadašnji pristupi i postojeći zaključci o prihvatanju prakse inhumacije na pomenutom prostoru, i pokušava da se na čitav problem baci svetlo iz drugačijeg ugla. Za argumentovanje ponuđenih pogleda uzeti su primeri sa lokaliteta na područjima provincija Gornje Mezije (Viminacijum, Singidunum, Skupi, Municipijum DD), jugoistočnog dela Donje Panonije (Sirmijum, Mursa) i istočnog dela Dalmacije (Dokleja, Municipijum S..., Domavia). Odmah je potrebno staviti napomenu o kvalitativnoj i kvantitativnoj razlici podataka sa pojedinačnih lokaliteta, što je okolnost koja umanjuje pouzdanost generalizacija koje će biti iznete, a njihov karakter pretvara u vrstu opštih pretpostavki. Tekst je organizovan tako da najpre ukazuje na opšti teorijski pristup funerarnoj arheologiji koji je ovde upotrebljen, zatim skreće pažnju na manjkavosti postojećih pogleda pomoću kojih se

\footnotetext{
${ }^{*}$ Rad je nastao kao fazni rezultat republičkog projekta broj 177002 pod nazivom Vojvođanski prostor u kontekstu evropske istorije.
} 
fenomen prihvatanja inhumacije tumači na prostoru bivše SFRJ, ${ }^{1}$ nakon čega nudi drugačija objašnjenja najpre na opštem nivou, a zatim i diskutovanjem pojedinačnih primera sa centralnog Balkana.

\section{Arheologija pogreba: opšte pretpostavke i pristupi}

Aktivnosti povezane sa pogrebom predstavljaju jednu od najsloženijih oblasti za izučavanje i tumačenje unutar arheološke discipline. ${ }^{2}$ Kompleksnost postupka interpretacije pogrebnih praksi jednim delom proizlazi iz jedinog opšteg pravila koji za njih važi: da nema generalnih pravila i jedinstvenog pristupa u suočavanju problema ove vrtse. Drugim rečima, ne postoje generalizacije niti „najučestaliji ispravni pristup“ koje je moguće upotrebiti u svim ili većem broju izučavanih slučajeva. ${ }^{3}$ Tumačenja zavise, pre svega, od teorijske perspektive istraživača koji ih nude, i za svaki pojedinačni primer moguće je upotrebiti različiti pristup, ili više njih. Ipak, u sagledavanju problema pogreba postoje izvesni elementi oko kojih se slaže većina arheologa i antropologa. Pre svega, na koji god način da pristupimo pogrebnim praksama, i iz koje god teorijske perspektive, uvek je reč o reakciji zajednice na prestanak telesnog života nekog njenog člana, fenomenu prevazilaženja posledica smrti i manipulaciji beživotnim telom, odnosno rešavanju problema njegovog neminovnog raspadanja. Dakle, pogreb kao praksa/aktivnost/ritual za cilj uvek ima neku vrstu odlaganja kadavera na odgovarajući, društveno ustanovljeni način, iako načini odlaganja mogu drastično da se razlikuju za pojedince/ke, društvene grupe, čitave zajednice, kao i kroz vreme. ${ }^{4}$ Sledeće manje-više prihvaćeno stanovište tiče se razlikovanja procesa pogreba od samog čina sahrane. Za razliku od trenutka kada se telo / njegov deo / kremirani ostaci na neki način odlažu (što bi bila sahrana), aktivnosti koje prate ovaj čin mogu da se odvijaju i pre i posle njega, i mogu da podrazumevaju složene i mnogobrojne radnje (i one bi zajedno sa sahranom činile proces pogreba). Ovu okolnost uvek treba imati na umu budući da se u arheologiji susrećemo samo sa delovima procesa pogreba, i to, veoma često, samo onim koji su vezani za sahranjivanje i neposredne prateće aktivnosti. Dodatno, arheološkim metodima moguće je otkriti samo deo materijalnih elemenata procesa, odnosno tragove konačnog

\footnotetext{
${ }^{1}$ Ovo područje se uzima kao relevantno jer su ključni radovi koji se bave pitanjem inhumacije u rimsko doba nastali u periodu postojanja bivše Jugoslavije i kao geografski okvir su uzimali upravo njenu teritoriju. Takođe, međusobni uticaj autora iz ondašnje iste države imao je presudnu ulogu u formiranju tumačenjskih pristupa ovom problemu koji važe i danas.

${ }^{2}$ Upor. Mike Parker Pearson, The Archaeology of Death and Burial, Stroud 2003.

${ }^{3}$ Frederik Fahlander, Terje Oestigaard, The Materiality of Death: Bodies, Burials, Beliefs, The Materiality of Death: Bodies, Burials, Beliefs (Eds. Frederik Fahlander and Terje Oestigaard), BAR International Series, Oxford 2008, 1-2.

${ }^{4}$ F. Fahlander, T. Oestigaard, The Materiality of Death, 5-6; Liv Nilsson Stutz, More than Metaphor: Approaching the Human Cadaver in Archaeology, The Materiality of Death: Bodies, Burials, Beliefs (Eds. Frederik Fahlander and Terje Oestigaard), BAR International Series, Oxford 2008, 19-28; Frederik Fahlander, The Materiality of Serial Practice, a Microarchaeology of Burial, Uddevalla 2003, 74-75; John Robb, Burial Treatment as Transformations of Bodily Ideology, Performing Death: Social Analyses of Funerary Traditions in the Ancient Near East and Mediterrenean (ed. Nicola Laneri), Oriental Institute, University of Chicago, Chicago 2007, 289.
} 
ishoda (samo) onih aktivnosti od kojih su ostali materijalni ostaci. ${ }^{5}$ Iz ovih razloga je neophodno napustiti iluziju o mogućnosti potpune i precizne rekonstrukcije čitavog procesa pogreba na osnovu arheoloških podataka.

Još jedno rašireno stanovište, koje će biti prihvaćeno i u ovom radu, tretira pogrebne aktivnosti kao ritual / niz rituala, i to u smislu (manje-više) precizno određenih obrazaca ponašanja (i načina izvođenja) pomoću kojih se izražavaju (neke) društvene vrednosti zajednice. ${ }^{6}$ Iako je sam pogreb obrednog karaktera, ovo ne znači da se radi o ritualima koji su neminovno vezani za religiju ili filozofsko viđenje „drugog sveta“, niti da obredni tretman mrtvog tela direktno odražava društvenu stvarnost zajednice. $^{7}$ Jednostavnije rečeno, aktivnosti za vreme pogreba uopšte ne moraju da budu utemeljene u religijskoj doktrini ili filozofskom učenju (bilo preminulog/e ili zajednice), već mogu da budu ishod drugih (,zemaljskijih“) socijalnih kategorija kakve su status, rod, materijalno stanje, politička uverenja, ideologija, zakonske regulative itd. Slično tome, načini na koji se pogreb vrši i „protokoli“ koji se upotrebljavaju ne moraju da odslikavaju realne socijalne odnose koji važe unutar zajednice ili na relaciji umrli/a-zajednica, već mogu da budu konstruisani tako da realne odnose zamaskiraju, trenutno ublaže ili suspenduju. ${ }^{8}$ Mrtvo telo i njegov tretman mogu da budu manipulisani za potrebe socijalne realnosti živih i stoga ne moraju da imaju nikakve veze sa socijalnom personom umrlog/e. Pokojnik/ca i pogrebni rituali često predstavljaju projektovanu i idealizovanu sliku nastalu zarad određenih ciljeva zajednice koja pogreb vrši, i to usled često prenebregavane, a osnovne, činjenice da mrtvi ne sahranjuju sebe već to čine oni koji su nakon njihove smrti ostali u životu. ${ }^{9}$ Pogrebne obrede, dakle, ustanovljavaju i sprovode živi pripadnici zajednice i zbog toga je pogreb stvar koja se direktno tiče njih i njihovih društvenih pozicija, te je verovatno da će njegovo značenje i izvođenje biti vezano za socijalnu strukturu zajednice (bez obzira koliko će „realno“ ili projektovano ona biti predstavljena). Takođe je veoma bitno da pogreb (ili sahrana) može da predstavlja događaj javnog karaktera koji mobiliše širi deo zajednice (nego što je, na primer, porodica), i predstavlja pogodno dešavanje za potvrđivanje ili preispitivanje ideologije, odnosno održavanje, sticanje ili gubitak socijalnih uloga i relacija pojedinaca, grupa ili čitave zajednice. ${ }^{10}$

Široko prihvaćena perspektiva za sagledavanje smrti i pogreba je stanovište da ove pojave za mnoga ljudska društva predstavljaju obrede prelaza. Ovu generalizaciju je još početkom XX veka ponudio Arnold van Genep i od tog perioda ona nije gubila na

\footnotetext{
${ }^{5}$ Ian Morris, Death-Ritual and Social Structure in Classical Antiquity, Cambridge 1992, 13; M. Parker Pearson, The Archaeology of Death, 5.

${ }^{6}$ Mike Parker Pearson, Mortuary Practices, Society and Ideology: an Ethnoarchaeological Study, Symbolic and Structural Archaeology (ed. Ian Hodder), Cambridge University Press, Cambridge 1982, 101; I. Morris, DeathRitual, 8-9.

${ }^{7}$ I. Morris, Death-Ritual, 1-2.

${ }^{8}$ F. Fahlander, The Materiality of Serial Practice, 78-79.

${ }^{9}$ M. Parker Pearson, The Archaeology of Death, 3; F. Fahlander, The Materiality of Serial Practice, 76; Сташа Бабић, Поглаварство и полис: старије гвоздено доба централног Балкана и грчки свет, Београд 2004, 78.

${ }^{10}$ M. Parker Pearson, Mortuary Practices, 101, 112; M. Parker Pearson, The Archaeology of Death, 32-33; Nicola Laneri, An Archaeology of Funerary Rituals, Performing Death: Social Analyses of Funerary Traditions in the Ancient Near East and Mediterrenean (ed. Nicola Laneri), Oriental Institute, University of Chicago, Chicago 2007, 5-8.
} 
aktuelnosti i broju pristalica, iako je osnovna verzija doživljavala modifikacije ili pak potpuno neprihvatanje od strane pojedinih autora. Prema Van Genepu, smrt, pre svega, predstavlja prestanak jedne vrste bivstvovanja za pokojnika/cu, ali taj događaj označava i promenu stanja unutar same zajednice koja se odvija u trima osnovnim etapama. Prva od njih je tzv. preliminalna faza koju prate obredi vezani za odvajanje pokojnika od oblika postojanja i iz konteksta pre trenutka smrti, kao i odvajanje porodice/zajednice od preminulog člana i dotadašnjeg ,normalnog“ načina života uz njega/nju. Druga faza je liminalna i ona podrazumeva aktivnosti i obrede vezane za tranzicioni period, deonicu između stanja kada je pokojnik/ca bio/la u životu i konačnog stanja pridruživanja mrtvima. Ova faza za porodicu/zajednicu predstavlja vanredno stanje koje je često povezano sa nečistoćom i izmenama ponašanja. Treća etapa su tzv. postliminalni obredi koji označavaju potpuno uključivanje umrlog/le u svet mrtvih, odnosno integraciju članova zajednice natrag u „normalno“ stanje ali bez pokojnika/ce. ${ }^{11}$ Naravno, ponuđena shema ne predstavlja univerzalno primenjivo pravilo, ali osnovnu ideju o konceptu prelaza/promene uzimam kao opravdanu, jer smatram da smrt člana zajednice zaista menja dotadašnje stanje i percepciju članova zajednice, iz jednostavnog razloga što određena individua prestaje da bude prisutna i gubi mogućnost delanja i društvenog sudelovanja u obliku kakav podrazumeva živo telo.

Inhumacija na centralnom Balkanu ranorimskog perioda: postojeća tumačenja

Arheološkim istraživanjima nekropola iz rimskog perioda na prostoru centralnog Balkana otvoreno je pitanje prihvatanja inhumacije kao načina tretmana tela. Ponuđene interpretacije zasnivale su se na tezi da je kremacija dominirala u zapadnom delu Carstva dok je inhumacija upotrebljavana u istočnoj polovini, što je generalno prihvaćeno stanovište u klasičnoj arheologiji rimskog perioda. ${ }^{12}$ Kako je na prostoru centralnog Balkana kremacija bila dominantni način tretmana tela u prerimskom periodu, pretpostavljeno je da se ona prvenstveno može povezati sa autohtonim populacijama i da predstavlja tradiciju koja se zadržala i nakon inkorporacije ovih prostora u Rimsko carstvo. Dodatno utemeljenje ovakvog gledišta pronađeno je u grobnim jamama specifičnih oblika koje su protumačene kao lokalne/regionalne kulturne karakteristike. Iz ovih premisa nastalo je opšteprihvaćeno stanovište da su incineracija pokojnika i polaganje ostataka u grobove specifičnih oblika prakse koje karakterišu autohtono stanovništvo. ${ }^{13}$ Sledstveno tome, grobovi sa skeletnim ostacima iz ranocarskog perioda ${ }^{14}$

\footnotetext{
${ }^{11}$ Arnold van Gennep, The Rites of Passage, Death, Mourning, and Burial: A Cross-Cultural Reader (ed. Antonius C. G. M. Robben), Blackwell Publishing, Malden-Oxford 2004; Ian Morris, Burial and Ancient Society: the Rise of Greek City-State, Cambridge University Press, Cambridge 1987, 29-31; I. Morris, DeathRitual, 9-10.

${ }^{12}$ Jon Davies, Death, Burial and Rebirth in the Religions of Antiquity, London 1999, 149; I. Morris, DeathRitual, 52.

${ }^{13}$ Драгослав Срејовић, Римске некрополе раног Царства у Југославији, Старинар н.с. 13-14/1962-1963, Београд 1965, 83-84; Milutin Garašanin, Razmatranje o nekropolama tipa Mala Kopašnica-Sase, Godišnjak VI, Centar za balkanološka ispitivanja ANU BiH 4, Sarajevo 1968, 5-35; Александар Јовановић, Римске
} 
protumačeni su kao sahrane doseljenih populacija, dok je pod uticajem generalne povezanosti prakse inhumacije i rimskog Istoka, pretpostavljeno da se radilo o doseljenicima orijentalnog porekla. Ovakav tumačenjski model je opšteprihvaćen od strane autora na prostoru bivše SFRJ i predstavlja dominantni način sagledavanja pojave inhumacije u rimskom periodu centralnobalkanskog područja. ${ }^{15}$ Drugačije stanovište ponudio je D. Srejović još 1965. g. ukazujući da je prihvatanje inhumacije fenomen koji je vezan za područja pod jakim rimskim uticajima (urbani centri, limes) i da se upravo na njima i najranije pojavljuje. Prema njegovom mišljenju, praktikovanje spaljivanja bilo je posledica sukoba između domorodačke i rimske kulture, dok je napuštanje ovog tretmana tela i prihvatanje inhumiranja povezano sa prevazilaženjem te krize, odnosno romanizovanjem starosedelaca. Iako je romanizaciju video kao glavno objašnjenje za napuštanje kremacije i prihvatanje inhumacije, Srejović se složio da je naseljavanje populacija sa Istoka i prihvatanje hrišćanstva takođe uticalo na ovu pojavu, ali u manjoj meri. ${ }^{16}$ Njegova zapažanja, međutim, ostala su bez uticaja na istraživače koji su se bavili ovim pitanjima.

некрополе на територији Југославије, Београд 1984, 100-110; Aleksandar Jovanović, Romanization and ethnic elements in burial practice in the southern part of Pannonia Inferior and Moesia Superior, Burial, Society and Context in the Roman World (Eds. John Pearce, Martin Millet and Manuela Struck), Oxbow Books, Oxford 2000, 204-214; Љубица Зотовић, Некрополе спаљених покојника на територији Горње Мезије, Лесковачки зборник 8, Лесковац 1968, 19-30; Љубица Зотовић, Промене у формама сахрањивања забележене на територији Југославије у времену од I до VI века, Лесковачки зборник 10, Лесковац 1970, 19-24; Петар Милошевић, Археологија и историја Сирмијума, Нови Сад 2001, 161-163; Иван Микулчић, Раноримски скелетни гробови из Скупа, Старинар 24-25, Београд 1975, 89-102; Душанка Коракевик, Состојбата на археолошките ископувана на античко Скупи, Macedoniae acta archaeologica 3, Скопје 1977, 143-180; Snežana Golubović, Graves of the Mala Kopašnica-Sase Type at the Viminacium Cemetery from an Aspect of thir Ethnic Origin, The Thracian World at the Crossroads of Civilizations II (ed. Petre Roman), Institutul Roman de Tracologie, Bucharest 1998, 247-260; Miomir Korać, Snežana Golubović, Viminacium 2, Više grobalja, Beograd 2009, 524-525.

${ }^{14}$ Model se odnosi na period pre opšteg prihvatanja inhumacije u zapadnim provincijama Carstva koje se dogodilo tokom II i početkom III veka.

${ }^{15}$ И. Микулчић, Раноримски скелетни гробови, 99; Д. Коракевик, Состојбата, 164-169; А. Јовановић, Римске некрополе, 99, 114, 128-129; A. Jovanović, Romanization and ethnic elements, 210-212; Aleksandar Jovanović, Inhumation in Moesia Superior in the 1st to 3rd century AD, Körpergräber des 1.-3. Jahrhunderts in der Römischen Welt. Internationales Kolloquium, Frankfurt am Main, 19.- 20, November 2004 (Hsg. Andrea Faber, Peter Fasold, Manuela Struck und Marion Witteyer), Archäologisches Museum Frankfurt, Frankfurt, 2007, 129-136; Aleksandar Jovanović, Prologue to the Research of Inhumation in Moesia Superior in the First to Third Centuries A.D., Гласник Српског археолошког друштва 22, Београд 2006, 23-44; Љубица Зотовић, Јужне некрополе Виминацијума и погребни обреди, Viminacium 1, Пожаревац 1986, 44; Љ. Зотовић, Промене, 9; П. Милошевић, Археологија и историја, 164-165; Slobodan Fidanovski, Nekropole municipijuma DD u svetlu novih istraživanja, Glasnik Muzeja Kosova 15-16 (1987-1988), Prišitina 1988, 3234; Драгана Спасић-Ђурић, Прилози као знак порекла у једном гробу из Виминацијума, Viminacium 15, Пожаревац 2007, 175-200; Драгана Спасић-Ђурић, Медаљон и други налази из гроба Г1733 из Виминацијума, Гласник Српског археолошког друштва 23, Београд 2007, 323-340; Hermine GörickeLukić, Sjeveroistočna nekropola rimske Murse, Zagreb-Osijek 2000, 96; Snežana Golubović, Sahranjivanje u Viminacijumu od I do IV veka. Doktorska disertacija, Filozofski fakultet, Univerzitet u Beogradu, 2004, 29, 31, 36, 113; M. Korać, S. Golubović, Viminacium 2, 517; Ленче Јованова, Дафина Михаилова, Скупи - Источна некропола - истражувања 1994. год., Macedoniae acta archaeologica 15 (1996-1997), Скопје 1999, 236.

${ }^{16}$ Д. Срејовић, Римске некрополе, 72-73. 
Mada na prvi pogled iznenađujuće, i dominantna i Srejovićeva interpretacija imaju mnogo zajedničkog, budući da su formirane na istim teorijskim pretpostavkama. Preovlađujući tumačenjski narativ o prihvatanju inhumacije na području centralnog Balkana u ranocarskom periodu se zasniva na dva ključna koncepta. Prvi je pretpostavka da se inhumacija može smatrati kulturnom praksom koja karakteriše rimski Istok i sve njegove populacije, a drugi je da se inhumacija morala širiti migracijama stanovništva orijentalnog porekla koje je tu kulturnu praksu donelo sa sobom, praktikovalo je na novonastanjenim prostorima i svojim uticajem širilo dalje. Oba upotrebljena postulata predstavljaju temelje teorijsko-interpretativnog okvira kulturno-istorijske arheologije koja podrazumeva neraskidivu i normativnu povezanost između jednog područja, ljudi koji žive na njemu i kulturnih praksi svih vrsta. Preciznije, ovaj teorijski okvir se zasniva na pretpostavci da se arheološki ostaci (odnosno aktivnosti koje oni indiciraju) na jednom prostoru, ukoliko pokazuju sličnost, mogu smatrati proizvodom populacije koja deli istu kulturu, odnosno ima iste društvene vrednosti i ideje važeće za svakog njenog pripadnika/cu, i da se takva kultura može poistovetiti sa etnicitetom ili rasom. Prema ovom viđenju, stečene kulturne navike su stabilne, statične i održavaće se gotovo uvek i svuda, dok će promene unutar jedne kulture najčešće biti izazvane ili kulturnim kontaktom (tj. difuzijom ideja, „kulturnim impulsom“), ili pak migracijom, odnosno dolaskom novog stanovništva koje donosi i nove kulturne prakse i njihove materijalizacije. ${ }^{17}$ Poteškoće sa ovim pristupom su brojne i tiču se, pre svega, neposrednog poistovećivanja materijalne kulture sa etničkim identitetom i pretpostavljanja jednog i jedinstvenog načina njene upotrebe iza koje stoje ista ideološka ubeđenja koja su duboko usađena u (pod)svest čitave populacije. U ovakvom konceptualizovanju prošlosti utkano je moderno shvatanje nacije i nacionalnih teritorija/dražava, po kojem je okosnica formiranja kolektivnog identiteta deljenje istog jezika, (zamišljenih) zajedničkih predaka i prošlosti, religije i precizno definisane teritorije. Na taj način stvoreno je predrasudno gledište po kojem su populacijama iz prošlosti kao najvažnije pripisane/učitavane one forme kolektivnog organizovanja i okupljanja (nacija i nacionalna teritorija) koje su važile u vreme nastanka kulturno-istorijske paradigme (i važe do danas), dok mogućnost da su druge vrste kolektivnih identiteta bile važnije nije uzimana u obzir ili je svedena na minimum. Upravo je sa ovog stanovišta u arheološkim ostacima najpre prepoznavan odraz etničkih identiteta (a ne, recimo, statusnih, rodnih, starosnih, političkih, profesionalnih itd.), iako ne postoji pravolinijska povezanost između kulturnih sličnosti i razlika sa jedne i etničkih granica sa druge strane. ${ }^{18}$ U slučaju na koji se odnosi ovaj rad postojeće objašnjenje podrazumeva da su sve populacije sa Istoka delile identične kulturne prakse koje su nastale usled jake helenizacije tog područja u helenističkom periodu. Prema ovom viđenju, na Istoku su

\footnotetext{
${ }^{17}$ Bjørnar Olsen, Od predmeta do teksta: teorijske perspektive arheoloških istraživanja, Beograd 2002, 30-43, 118-121; Метју Џонсон, Археолошка теорија, Београд 2009, 33-38.

${ }^{18}$ Detaljnije o ovim problemima vid.: Sean Jones, The Archaeology of Ethnicity, Constructing identities in past and present, London - New York 1997; Sean Jones, Discourses of identity in the interpretation of the past, The Archaeology of Identities: a Reader (ed. Timothy Insoll), London - New York 2007, 44-58; Sam Lucy, Ethnic and Cultural Identities, The Archaeology of identity: Approaches to gender, age, status, ethnicity and religion (Margarita Díaz-Andreu, Sam Lucy, Stasa Babić and David N. Edwards), London - New York, 2005, 86-109; Staša Babić, Arheologija i etnicitet, Etnoantropološki problem god. 5 sv. 1, Beograd 2010, 137-149.
} 
živeli kulturno superiorni ljudi (budući da su helenizovani) koji svoje prakse nisu menjali čak ni prilikom emigracije, već su, naprotiv, u novonaseljenim prostorima vršili kulturne uticaje različitih karaktera, uključujući i širenje prakse inhumacije. Ovakve pretpostavke su problematične jer se područje rimskog Istoka ne može tretirati kao kulturna, etnička ili populaciona celina, kao što pretpostavljena duboka helenizacija zapravo delimično važi za elitne slojeve stanovništva na Istoku. ${ }^{19}$ Dodatno, pokazano je da se imigranti sa Istoka ne mogu arheološki razlikovati čak ni na lokalitetima za koje je (na osnovu literarnih i epigrafskih izvora) njihovo prisustvo izvesno. ${ }^{20}$ Takođe, narativ o neminovnim blagotvornim uticajima helenske kulture formiran je usled stanovišta da ona predstavlja kolevku evropske civilizacije, i da se može smatrati jednim od vrhunaca koji su ljudi (kao vrsta) ikada dosegli, što je pozicija opterećena predrasudnim, jednostranim i subjektivnim vrednovanjem prošlosti. ${ }^{21}$ Sumirano, niti se pojava inhumacije može smatrati posledicom doseljavanja velikog broja ljudi sa Istoka, niti se ti doseljenici mogu tretirati kao nosioci jedinstvenog helenističkog impulsa koji je „kulturno virulentno“ delovao na populacije koje su živele na centralnom Balkanu u ranocarskom periodu.

Iako je D. Srejović ukazao da se inhumacija ne može jednostrano vezati za orijentalne doseljenike ili širenje orijentalnih verskih učenja, njegovi argumenti se zasnivaju na, suštinski, istoj pretpostavci o uticajima superiorne kulture i doseljenicima kao njenim nosiocima. Razlika je u tome što je kao izvorište ovoga puta viđen Rim, područje Italije i zapadnih provincija Carstva. Unutar ovog modela centralna uloga poverena je konceptu romanizacije koji je razvijan krajem XIX i tokom prve polovine XX veka na prostoru Velike Britnije, Nemačke i Francuske, a zasnovan je na snažnim kolonijalističkim, imperijalističkim i evropocentrističkim predubeđenjima (kombinovanim sa konceptom sociokulturne evolucije) koja su dominirala intelektualnim krugovima tog perioda. Romanizacija u osnovnom obliku označava proces širenja rimske kulture u vidu paketa koji se sastojao od urbanizacije, latinskog jezika, religijskog sinkretizma i rimskih kulturnih praksi. Ove prakse shvatane su kao superiorni način života, a njihovo širenje kao civilizovanje populacija koje su živele „na nižem stupnju društvenog razvoja“. Kontakti rimske i domorodačkih kultura koncipirani su kao sučeljavanje sa oštrom granicom koja je ili prevazilažena prihvatanjem seta rimskih kulturnih normi, ili je ostajala na snazi i autohtone zajednice petrifikovala na nižoj lestvici ljudskosti. Osnovni problem sa konceptom romanizacije je svođenje kompleksnih socijalnih dešavanja na proste binarne

\footnotetext{
${ }^{19}$ Fergus Millar, 1993. The Roman Near East, 31 BC-AD 337, London - Cambridge-Mass. 1993, 11, 234 - 235; Warwick Ball, Rome in the East. The transformation of an empire, London - New York 2000, 3, 4-5, 11, 17, 23; Kevin Butcher, The Roman Syria and the near East, London 2003, 82-83, 121, 140-141, 270-271, 332-334; Lidewijde de Jong, Becoming a Roman province: An analysis of funerary practices in Roman Syria in the context of empire, Unpublished Dissertation, Stanford University, 2007, 4, 7, 9, 11; Jesper Majbom Madsen, The Romanization of the Greek elite in Achaia, Asia and Bithynia: Greek Resistance or Regional Discrepancies?, 1415, 18, 23, 27, 32-33, http://www.pontos.dk/publications/papers-presented-orally/oralfiles/Mad_romanisationelite.pdf. 15. 05. 2011.

${ }^{20}$ John Bert Lott, The Neighborhoods of Augustan Rome, Cambridge 2004, 22-23. O problemu identifikacije orijentalnog stanovništva na području Gornje Mezije upor.: В. Д. Михајловић, Археолошки и епиграфски показатељи досељавања оријенталног становништва на територији Горње Мезије, дипломски-мастер рад, Филозофски факултет, Универзитет у Београду, 2009.

${ }^{21}$ Uрог.: Сташа Бабић, Гричи и други: античка периепџија и периепџија антике, Београд 2008.
} 
opozite u kojima je jedna (rimska) strana favorizovana, kao i ignorisanje mogućnosti međusobnih prožimanja koja su mogla da dovedu do čitavog niza stvaranja jedinstvenih socijalnih realnosti sa neograničenim kombinovanjima i reinterpretacijama značenja kulturnih praksi i njihovih materijalizacija. ${ }^{22}$ U svakom slučaju, iako D. Srejoviću pripada zasluga za skretanje pažnje na mogućnost drugačijeg scenarija za širenje inhumacije, kao i za ukazivanje na uticaj opštih tokova u Carstvu koji su tome doprinosili, manjkavost njegovog modela leži u pretpostavljenom mehanizmu širenja ove prakse.

\section{Praksa inhumacije u Rimskom carstvu: drugačija stanovišta}

U prethodnom delu je skrenuta pažnja na probleme sa dosadašnjim tumačenjima širenja inhumacije na centralnom Balkanu. Imajući u vidu ukazane nedostatke, smatram neophodnim da se umesto doseljenika i superiornih kulturnih uticaja uzmu u obzir i drugačija objašnjenja. Usled velikog prostranstva na koje se problem generalno odnosi, srazmerno nedovoljne istraženosti i različitih perspektiva istraživača, postoji mnoštvo različitih interpretacija. Tako se širenje inhumacije objašnjava modelima od uvođenja nove mode korišćenja sarkofaga, preko „renesanse“ predrimskih pogrebnih običaja, novog načina iskazivanja socijalnih položaja, do pretpostavke o ispošćavanju šuma koje je doprinelo poskupljenju drvne građe i napuštanju kremacije. ${ }^{23}$ Uzimajući u obzir da je širenjem inhumacije obuhvaćen čitav niz lokalnih pogrebnih sistema, ${ }^{24}$ nije izgledno da je pokopavanje tela imalo identično značenje za svaki grob, na svakoj geografskoj odrednici i u svakom trenutku. Ipak, pošto se inhumacija proširila u relativno kratkom vremenskom periodu diljem zapadnog dela Imperije, moguće je pretpostaviti da su izvesni razlozi imali generalni uticaj, odnosno da su postojali opšti socijalni preduslovi koji su pogodovali prihvatanju pokopavanja tela. Iz ovih razloga je neophodno upotrebiti model koji uzima u obzir lokalne socijalne kontekste i značenja inhumacije unutar njih, i istovremeno objašnjava razloge za njeno masovno prihvatanje.

Još 1932. g. Artur Nok (Arthur Nock) se osvrnuo na pojavu inhumacije kao fenomena koji je zahvatio čitavu Imperiju. Nudeći primere iz Rima i provincija, Nok je zaključio da ova promena ne može da se poveže sa širenjem mističnih i orijentalnih kultova, kao ni sa hrišćanstvom, te i ne može da se tretira kao pokazatelj početka drastično različite konceptualizacije zagrobnog života. Umesto ovih razloga ponudio je objašnjenje po kojem je ekspanzija inhumacije bila uzrokovana „modnim trendom“, tako što su je najpre prihvatili elitni slojevi u Rimu od kojih se postepeno širila i među nižim slojevima

\footnotetext{
${ }^{22}$ O romanizaciji između ostalih: Richard Hingley, Globalizing Roman Culture: Unity, Diversity and Empire, London - New York 2005; Peter S. Wells, The Barbarians Speak: How the Conquered Peoples Shaped Roman Europe, Princeton-Oxford 1999; Greg Woolf, Becoming Roman: The Origins of Provincial Civilization in Gaul, Cambridge 1998; Janet Huskinson, Looking for Culture, Identity and Power, Experiencing Rome: Culture, Identity and Power in the Roman Empire (ed. Janet Huskinson), London, 2000, 3-27.

23 Andrea Faber, Peter Fasold, Manuela Struck, Marion Witteyer., Einleitung, Körpergräber des 1.-3. Jahrhunderts in der Römischen Welt. Internationales Kolloquium, Frankfurt am Main 19.- 20, November 20042004 (Hsg. Andrea Faber, Peter Fasold, Manuela Struck und Marion Witteyer), Archäologisches Museum Frankfurt, Frankfurt 2007, 12-13.

${ }^{24}$ I. Morris, Death-Ritual, 41.
} 
rimskog društva. Širenje inhumacije bilo je stimulisano popularizacijom upotrebe sarkofaga, koja se dogodila ili pod uticajima njihove upotrebe na Istoku, ili usled „renesanse“ etrurskih običaja u centralnoj Italiji. ${ }^{25}$ Šezdeset godina kasnije, Ijan Moris (Ian Morris) je ponovo pretresao ova pitanja i složio se da je prihvatanje inhumacije bilo stvar mode. Njegov argument protiv objašnjenja ove pojave popularizacijom mističnih ili orijentalnih kultova je metodološke prirode: ovaj interpretativni model je razvijen pod snažnim uticajem „,intelektualističkog“ pristupa koji je podrazumevao da su pogrebni rituali oblik filozofskih spekulacija o kosmosu, i koji se koncentrisao na njihov lični i psihološki sadržaj pre nego na društveni kontekst. Umesto pitanja kako se uopšte došlo na ideju o upotrebi inhumacije, Moris daje prioritet pitanju šta je ova praksa značila u kontekstu socijalnih odnosa pojedinaca i grupa. Po njemu, inhumacija je uvedena u atmosferi filhelenizma koji je vladao u II v. (pogotovu pod Hadrijanom i Markom Aurelijem) unutar carskih i elitnih krugova Rima, sa važnim naglaskom da njeno prihvatanje nije označavalo pasivno preuzimanje grčkih/helenističkih običaja već njihovu aktivnu reinterpretaciju i upotebu u specifičnom (rimskom) društvenom kontekstu. Kada je ovaj način tretmana tela jednom uveden, u toku jedne generacije se proširio među bogatim slojevima Rima. Iako je promena bila samo formalana, ona je bila način iskazivanja pripadnosti elitnim delovima društva, bez obzira da li je najpre prihvaćena u krugu cara a zatim preuzeta od elita ili je proces išao obrnutim tokom. Širenje inhumacije u provincijama, prema ovom modelu, odigravalo se zahvaljujući ohrabrivanju prakse podražavanja aktivnosti iz Rima koja je postojala kod lokalnih elita, od kojih se potom običaj širio dalje. ${ }^{26}$ Bez obzira da li se sa Morisom složimo u vezi sa hronologijom ili smerom i načinom kojim se praksa inhumacije širila, ${ }^{27}$ prihvatam deo njegovog modela koji ukazuje da je inhumacija vezana za socijalno-političku strukturu rimskog društva i da predstavlja njenu simboličku artikulaciju. Drugim rečima, smatram da je inhumacija bila relevantna unutar tzv. „globalne“ rimske kulture koja je podrazumevala društvene povezanosti i postojanje mreža organizovanih oko (u osnovi) jedinstvenog političkog sistema i hijerarhijskog poretka. Prema tome, inhumacija je mogla da predstavlja strategiju iskazivanja socijalnih pozicija, odnosno pripadnosti onim delovima stanovništva koji su bili povezani sa rimskim (urbanim) društvom u najširem smislu reči (naravno, sa mnogobrojnim varijacijama na prostornoj i socijalnoj skali). ${ }^{28}$ Shvaćena na ovakav način, inhumacija gubi ulogu indikatora etničke pripadnosti i indeksa romanizacije budući da je njeno praktikovanje moglo biti stvar izbora (pojedinca ili različitih grupnih kategorija) povezanog sa procenom simboličkog kapitala koji se time dobijao. Razumljivo, prihvatanje inhumacije nije automatski moralo da označava promenu ostalih identiteta

\footnotetext{
${ }^{25}$ Arthur D. Nock, Cremation and Burial in the Roman Empire, The Harvard Theological Review vol. 25 no. 4, 1932, 321-359.

${ }^{26}$ I. Morris, Death-Ritual, 15, 32-40, 52-68.

${ }^{27}$ Prema nekim mišljenjima, inhumacija se pojavljuje i širi od strane gradske elite centralne Italije politički favorizovane u vreme Flavijevaca. Takođe, neka stanovišta ukazuju da je moguće dopustiti i obrnuti smer uticaja od često pretpostavljanog elita - niži društveni slojevi: A. Faber et al., Einleitung, 13.

${ }^{28}$ O "globalnoj“ rimskoj kulturi uporediti: R. Hingley, Globalizing Roman Culture, 72-116; G. Woolf, Becoming Roman, 106-206; Martin Pitts, Globalizing the local in Roman Britain: An anthropological approach to social change, Journal of Anthropological Archaeology vol. 27 no. 4, 2008, 493-506.
} 
socijalne persone, ${ }^{29}$ kao što su drugi segmenti pogreba i načini njegovog vršenja (grobni kontejneri, obeležja, prilozi, odeća itd.) mogli da budu korišćeni sa ciljem isticanja simboličkog diferenciranja različitih socijalnih kategorija koje su praktikovale inhumiranje (na primer rimski građani, slobodni ljudi bez rimskih prava, oslobođenici, zakonske, starosne i rodne kategorije). Takođe, ovim se napušta i problematični Nokov i Morisov koncept jednostavne imitacije elitnih društvenih slojeva jer ponuđeno viđenje ne podrazumeva inertno prihvatanje ove prakse zato što je „bila u modi“, već nudi mogućnost njenog širenja zbog specifičnih značenja koje je nosila, kao i verovatnoću lokalnih reinterpretacija i prilagođavanja tih značenja.

Inhumacija na centralnom Balkanu ranorimskog perioda: moguće tumačenje

Detaljna diskusija o širenju inhumacije na području centralnog Balkana onemogućena je skromnim stepenom istraženosti ranorimskih nekropola i malim procentom publikovanih rezultata dosadašnjih iskopavanja. Ovakva situacija doprinosi da se o pomenutom problemu može govoriti samo na najopštijem nivou i sa postojanjem rezervi zbog mogućnosti da se prihvatanje i značenje pokopavanja tela moglo razlikovati u različitim slučajevima. Ipak, u ovom radu se na prvom mestu poklanja pažnja potencijalnim opštim društvenim okolnostima koje su doprinele početku upotrebe inhumacije za šta su postojeća saznanja dovoljna bar u minimalnoj meri. Podaci koji se ovde uzimaju kao važni tiču se najranijih pojava grobova sa nespaljenim pokojnicima, odnosno njihovog hronološkog i brojčanog odnosa prema grobovima sa spaljenim pokojnicima. Pretpostavljam da će ovi podaci pružiti osnovu za diskusiju kada se inhumacija na centralnom Balkanu javlja u odnosu na generalni trend u Carstvu, da li se eventualna hronološka pravilnost može povezati sa nekim opštim regionalnim socijalnim strujanjima i da li se inhumacija na osnovu brojčanog odnosa prema kremaciji može smatrati „devijantnim“, „nenormativnim“ načinom tretmana umrlih tela. Prema dosadašnjim opštim zapažanjima inhumacija karakteriše nekropole urbanih centara ranocarskog perioda, ${ }^{30}$ dok se na nekropolama naselja neurbanog karaktera pojavljuje srazmerno kasno, u vreme kada je predstavljala gotovo isključivi tretman tela u čitavom Carstvu. ${ }^{31}$ Najraniji grobovi na nekropolama gradskih naselja okvirno su datovani u vreme

\footnotetext{
${ }^{29}$ U smislu da pokopavanje tela automatski označava da je osoba imala rimsko građansko pravo, bila deo imućnog sloja, bavila se određenom profesijom i slično.

${ }^{30}$ Д. Срејовић, Римске некрополе, 73; A. Jovanović, Prologue, 23.

${ }^{31}$ Dobri primeri za isključivu upotrebu kremacije su nekropole u Maloj Kopašnici, Ljaniku kod Preševa, starija faza nekropole u Laništu kod Baljevca: Слободан Фидановски, Татјана Цвјетићанин, Римска вила и некропола на локалитету Каменитица-Моравиште у Малој Копашници код Грделице, Археолошка истраживања Е -75, свеска 1 (ур. Марин Брмболић), Београд 2005, 49-123; Љ. Зотовић, Некрополе спаљених покојника; Александар Булатовић, Тони Чершков, Некропола спаљених покојника из римског периода у Љанику код Прешева, Гласник Српског археолошког друштва 23, Београд 2007, 141-157; Вера Богосављевић-Петровић, Структура античког становништва у долини Ибра, Рад Драгослава Срејовића на истраживању античке археологије (ур. Никола Тасић), Крагујевац 2003, 194-199. Iako je indikativno da na ovim nekropolama nisu pronađeni grobovi sa inhumiranim pokojnicima, nije moguće u potpunosti odbaciti da je pokopavanje tela ipak korišćeno i van urbanih centara ali da nam ti podaci trenutno nedostaju zbog neistraženosti. Potpuna prevaga inhumacije u periodu kasnog Carstva evidentna je (između ostalih) na primerima
} 
od kraja I do polovine II v., mada je preciznije hronološko opredeljenje kao i brojčani odnos inhumiranih prema kremiranim pokojnicima moguće izraziti jedino u slučaju Viminacijuma. Važno je napomenuti da diskusija o širenju inhumacije u obzir uzima grobove sa ostacima odraslih individua jer se smatra da je za decu do 15 godina starosti inhumacija bila preovlađujući način tretiranja tela već u najranijim fazama ranocarskih nekropola. $^{32}$

Na severoistočnoj nekropoli Murse, prema dosadašnjim saznanjima, inhumacija je korišćena paralelno sa kremacijom već od druge polovine I v. (grob 111), a njena upotreba je intenzivirana u periodu II v. ${ }^{33}$ Nažalost, drugi podaci izostaju što zbog devastacije ranorimskih grobova naknadnim sahranama, što zbog izostanka preciznog datovanja publikovanih grobnih celina. Slično tome, za nekropole Sirmijuma uopšteno je poznato da se najraniji grobovi sa skeletnim ostacima pripisuju periodu oko sredine II v., dok su druge pojedinosti o njima ostale neobelodanjene. ${ }^{34}$ Nekropole Singidunuma takođe ne pružaju detaljniju sliku o ranorimskim grobovima sa inhumiranim pokojnicima, prvenstveno zbog toga što većina do sada otkrivenih grobova pripada vremenu nakon sredine II v. Za Singidunum je uopšteno poznato da se pokopavanje i spaljivanje tela javljaju paralelno, verovatno još u prvoj polovini II v. ${ }^{35}$ Tri nekropole u blizini današnje Sočanice (Municipijum DD) nisu bile predmet detaljnih arheoloških istraživanja, pa je jedino poznato da se na lokalitetima Prisoje i Rudo polje pronalaze grobovi sa oba načina tretmana tela. Najstariji do sada poznati grob sa ostacima nespaljene individue pronađen je na prisojskoj nekropoli i datovan u vreme prve polovine II v. ${ }^{36}$ Nekropola na parceli $160 \mathrm{u}$ Skupima, koja je datovana u period od ranog I do ranog III v., sadržala je 92 groba od kojih je 8 bilo sa inhumacijom. Tačan odnos grobova iz perioda prva dva veka nije moguće predstaviti jer nekropola nije publikovana u celini. Najstariji publikovani grobovi sa inhumacijom datovani su u kraj I (grob 137) i sredinu II v. (grob 170). Deo nekropole u Skupima koji se nalazio na parcelama 169 i 170, i koji je pripisan orijentalnim doseljenicima, sadržao je 33 groba od kojih je 12 bilo sa kremacijom a 21 sa inhumacijom. Kako ni ovaj deo nekropole nije publikovan u potpunosti, nije moguće precizirati brojčani odnos skeletnih prema spaljenim pokojnicima, niti kvantitativne varijacije za ranocarsko doba. Na ovom delu istočne skupske nekropole, najstariji grobovi sa inhumacijom opredeljeni su u period oko sredine (grobovi 11 i 98) i druge polovine II v. (grobovi 8, 8a, 10, 129). ${ }^{37}$ Jugoistočna nekropola Dokleje sadržala je grobove sa inhumacijom od kojih su

neurbanih nekropola kod Sviloša i Beške u Sremu: Velika Dautova-Ruševljan, Kasnoantička nekropola kod Sviloša u Sremu, Novi Sad 2003; Mirjana Marjanski-Manojlović, Rimska nekropola kod Beške u Sremu, Novi Sad 1987.

${ }^{32}$ A. Jovanović, Prologue, 26; Љубица Зотовић, Часлав Јордовић, Viminacium 1, некропола Више гробаља, Београд 1990, 111-113; M. Korać, S. Golubović, Viminacium 2, 513.

${ }^{33}$ H. Göricke-Lukić, Sjeveroistočna nekropola, 96, 100-102.

${ }^{34}$ П. Милошевић, Археологија и историја, 164-165; Petar Milošević, Kompleks rimskih nekropola u Sirmijumu, nastanak, geneza i kraj, doktorska disertacuja, Filozofski fakultet, Univerzitet u Beogradu, 1978.

${ }^{35}$ Zoran Simić, Rezultati zaštitnih arheoloških istraživanja na prostoru jugoistočne nekropole Singidunuma, Singidunum 1, Beograd 1997, 44-45; Stefan Pop-Lazić, Nekropole rimskog Singidunuma, Singidunum 3, Beograd 2002, 39-51.

${ }^{36}$ S. Fidanovski, Nekropole municipijuma DD, 21-26, 29-30.

${ }^{37}$ И. Микулчић, Раноримски скелетни гробови, 89-93, 96-98. 
najraniji opredeljeni u period nakon vladavine Trajana. ${ }^{38}$ Zbog izostanka preciznog datovanja grobnih celina nemoguće je govoriti o drugim pojedinostima. Veoma interesantan slučaj predstavljaju dve nekropole otkrivene u Kominima (Municipijim S...) od kojih nijedna nije sadržala grobove sa inhumiranim pokojnicima mada su nekropole datovane u vreme od kraja I do III, odnosno od II do IV v. ${ }^{39}$ Slična situacija potpunog izostanka grobova sa nespaljenim pokojnicima zabeležena je na nekropolama u Sasama (Domavija), iako su i one formirane u vreme od I do polovine III v. ${ }^{40}$ Konačno, jedinu detaljniju sliku o pojavi inhumacije pruža viminacijumska nekropola Više grobalja zahvaljujući dvema objavljenim monografijama ${ }^{41}$ koje omogućavaju preciznije iskazivanje odnosa grobova sa spaljenim i nespaljenim pokojnicima. U razmatranje sam uzeo grobove koji su datovani od perioda I do kraja II v., i to tako što sam ovaj period podelio na manje hronološke okvire, uz pretpostavku da je datovanje grobnih celina u publikacijama izvedeno bar približno tačno. Zastupljenost grobova sa nespaljenim i spaljenim pokojnicima predstavljena je na grafikonu 1. Njihov brojčani odnos ukazuje da je inhumacija u odnosu na kremaciju zauzimala između 20 i $26 \%$ u svim periodima osim u prvim decenijama II v. kada je zastupljena sa $30 \%$ od ukupnog broja odraslih pokojnika. Udeo od 22\% grobova sa inhumacijom važi i za grobove koji su uopšteno datovani u period II v. (čiji odnos nije dat na grafikonu), pa je moguće da ovaj procenat predstavlja uobičajeno učešće upotrebe inhumacije na ovoj nekropoli u ranocarsko doba. Najveći porast korišćenja inhumacije (od 30\%) pripada periodu prvih decenija II v., te se postavlja pitanje da li je ovo posledica slučajnosti, načina datovanja grobova ili se radi o pokazatelju šireg prihvatanja inhumacije u ovo vreme. U tom pogledu od pomoći može biti grafikon 2 koji prikazuje brojčani odnos grobova sa inhumiranim pokojnicima odraslog i dečjeg uzrasta. Kao i u prethodnom slučaju, u periodu prvih decenija II v. beleži se povećanje broja grobova sa odraslima u odnosu na broj grobova sa decom. Drugim rečima, procenat inhumacije odraslih od kraja I do kraja II v. kreće se između 35 i 40\%, ${ }^{42}$ dok u prvoj polovini II v. dostiže $60 \%$ od ukupnog broja inhumiranih pokojnika svih uzrasta. Dakle, za prve dekade II v. procenat grobova odraslih inhumiranih osoba dostiže svoj vrhunac, kako u poređenju sa brojem grobova kremiranih pokojnika odraslog uzrasta tako i u odnosu na broj grobova sa inhumiranom decom. U ovom kontekstu je interesantno da se period vladavine Hadrijana generalno uzima kao vreme inicijalne ekspanzije prakse inhumacije u čitavom Carstvu. ${ }^{43}$ Iako su na nekropolama Viminacijuma, od njihovog

\footnotetext{
${ }^{38}$ Александрина Цермановић-Кузмановић, Оливера Велимировић-Жижић, Драгослав Срејовић, Античка Дукља, некрополе, Цетиње 1975, 258-259.

${ }^{39}$ Александрина Цермановић-Кузмановић, Комини - Мипісіріuт S..., некрополе, Београд 1998, 1-23.

${ }^{40}$ Milica Baum, Dragoslav Srejović, Prvi rezultati iskopavanja rimske nekropole u Sasama, Članci i građa za kulturnu istoriju istočne Bosne III, Tuzla 1959, 23-54; Milica Baum, Dragoslav Srejović, Novi rezultati ispitivanja rimske nekropole u Sasama, Članci i građa za kulturnu istoriju istočne Bosne IV, Tuzla 1960, 3-31; Dragoslav Srejović, Ispitivanje rimske nekropole u Sasama, Članci i građa za kulturnu istoriju istočne Bosne VI, Tuzla 1965, 7-49.

${ }^{41}$ љ. Зотовић, Ч. Јордовић, Viminacium 1, 55-110; M. Korać, S. Golubović, Viminacium 2, 25-438.

${ }^{42}$ Veoma sličan udeo pokazuju i grobovi sa inhumacijom koji su široko datovani u II v.: $41 \%$ odraslih prema $59 \%$ dece.

${ }^{43}$ I. Morris, Death-Ritual, 53; Jocelyn M. Toynbee, Death and Burial in the Roman World, London 1971, 40.
} 
nastanka, paralelno upotrebljavana oba tretmana tela, ${ }^{44}$ ova okolnost bi mogla da znači (ako se ne radi o slučajnosti i ako postojeći broj grobova uzmemo kao relevantan za ilustrovanje širih tendencija) da je opšti trend prihvatanja inhumacije doprineo intenzifikaciji njene upotrebe i u Viminacijumu. Još jedna interesantna koincidencija tiče se sticanja municipalnog prava Viminacijuma upravo u vreme Hadrijana, što nas vraća pitanju postojanja regionalnih preduslova koji su pogodovali širenju prakse inhumacije.

Prethodno navedeni primeri ukazuju da je na prostoru centralnog Balkana u nekim slučajevima (Mursa, Viminacijum, Skupi) inhumacija bila upotrebljavana još u drugoj polovini I v. paralelno sa dominantnim spaljivanjem pokojnika, dok se u drugim ona javlja do sredine II v. (Sirmijum, Singidunum, Municipijum DD, Dokleja). Iz ovoga proizlazi da inhumacija ne može da se tretira kao praksa koja je na centralni Balkan prvi put dospela u vreme njene generalne popularizacije (u prvoj polovini II v.), ali da je, sa druge strane, ta popularizacija verovatno znatno doprinela njenom širenju. U svakom slučaju, period poslednjih decenija I i prvih decenija II v. može se smatrati vremenom kada se na nekropolama urbanih naselja pojavljuje i intenzivno praktikuje pokopavanje nespaljenih tela pokojnika. Unutar istog perioda, naselja čije su nekropole ovde razmatrane dobila su municipalni/kolonijalni status ${ }^{45}$ što je značilo zvanično uključivanje u rimski politički sistem, i predstavljalo ishod procesa socijalnog restrukturiranja lokalnih zajednica koji je počeo inicijalnim kontaktima sa rimskom državom. Drugim rečima, inkorporacijom određene zajednice dešavale su se promene lokalnih društvenih ustrojstava tako što su njihova spajanja sa rimskim socio-političkim sistemom uzrokovala redefinisanje pojedinačnih i grupnih socijalnih uloga i napuštanje starih načina njihovog ispoljavanja. Tako su prerimski oblici političkog organizovanja bili zamenjeni institucijama municipijuma/kolonija koji su predstavljali osnovne jedinice rimskog socijalnog, političkog i kulturološkog ustrojstva. ${ }^{46}$ Ove promene bile su praćene uvođenjem novih društvenih i životnih praksi koje su dobijale specifične oblike lokalnim prilagođavanjima rimskih kulturnih i socijalnih okvira. Prilikom ovakvih rekonstrukcija lokalnih društava otvarale su se mogućnosti različitih simboličkih artikulacija novih pozicija upotrebom različitih sredstava. Grubo hronološko podudaranje pojave inhumacije i širenja rimskog socio-političkog sistema ${ }^{47}$ implicira da je jedan od načina iskazivanja promenjenih/stečenih/željenih socijalnih uloga bio i prihvatanje drugačijeg načina tretmana tela. Naravno, ovo ne znači da među inhumiranim pokojnicima treba prepoznati striktno određene socijalne grupe, budući da su inhumiranje mogle da praktikuju različite kategorije stanovništva. Takođe, ova pretpostavka ne označava da je inhumacija bila obavezni i sastavni deo „kulturnog paketa“ koji je doneo rimski socijalni sistem, već da se pre radilo o jednoj od mogućnosti koja je bila pitanje izbora (pojedinaca, porodica,

\footnotetext{
44 љ. Зотовић, Промене, 7; S. Golubović, Sahranjivanje u Viminacijumu, 36; M. Korać, S. Golubović, Viminacium 2, 523.

${ }^{45}$ Sa izuzetkom Municipijuma S... i Domavije koji svoje statuse dobijaju u drugoj polovini II / početku III v. odnosno početkom III v.

${ }^{46}$ Upor. napomenu 27; Louise Revell, Roman Imprialism and Local Identities, Cambridge 2009, 40-54; Phil Perkins, Lisa Nevett, Urbanism and Urbanization in the Roman World, Experiencing Rome, Culture, Identity and Power in the Roman Empire (ed. Janet Huskinson), London 2002, 213-244.

${ }^{47}$ Gledano generalno a ne isključivo u smislu municipalizacije.
} 
grupa). ${ }^{48}$ Da je upotreba inhumacije bila selektivna stvar koja je zavisila od značenja ove prakse u „lokalno-rimskim“ kontekstima ukazuju i nekropole Domavije i Municipijuma S... Iako su oba naselja imala municipalni status, ni na jednoj od istraženih nekropola nisu pronađeni grobovi sa nespaljenim pokojnicima što može da upućuje na odsustvo značaja inhumacije u lokalnim simboličkim sistemima. Sumirano, postoji mogućnost da je praksa inhumacije na području centralnog Balkana predstavljala jedan od fenomena koji su se pojavili u procesu uključivanja u nadregionalne/opšterimske socijalne strukture, procesu koji je rezultirao formiranjem novih provincijalnih društava. Izbor inhumacije mogao je da simbolizuje neku vrstu raskida sa pređašnjim društvenim ustrojstvom uz istovremeno iskazivanje pripadnosti novoj društvenoj realnosti koja se oslanjala i činila deo „globalne“ rimske socijalne ideologije. Pogreb kao ritual, koji se verovatno ticao šireg dela zajednice, (potencijalno) je predstavljao pogodno dešavanje za javno odašiljanje poruka o preminulom (ili onima koji su sahranjivali) i upravo je zbog toga mogao biti korišćen i kao vrsta ideološkog i simboličkog iskaza.

Izvori i literatura:

Бабић, Сташа, Гричи и други: античка перичепщија и перцеепџија антике, Београд 2008.

Бабић, Сташа, Поглаварство и полис: старије гвоздено доба централног Балкана и грчки свет, Београд 2004.

Babić, Staša, Arheologija i etnicitet, Etnoantropološki problem god. 5 sv. 1, Beograd, 2010, 137149.

Ball, Warwick, Rome in the East. The transformation of an empire, London-New York 2000.

Baum, Milica, Srejović Dragoslav, Prvi rezultati iskopavanja rimske nekropole u Sasama, Članci i građa za kulturnu istoriju istočne Bosne III, Tuzla 1959, 23-54.

Baum, Milica, Srejović Dragoslav, Novi rezultati ispitivanja rimske nekropole u Sasama, Članci i gradja za kulturnu istoriju istočne Bosne IV, Tuzla 1960, 3-31.

Богосављевић-Петровић, Вера, Структура античког становништва у долини Ибра, Рад Драгослава Срејовића на истраживању античке археологије (ур. Никола Тасић), Крагујевац 2003, 191-209.

Булатовић,Александар, Чершков Тони, Некропола спаљених покојника из римског периода у Љанику код Прешева, Гласник Српског археолошког друштва 23, Београд 2007, 141-157.

Butcher, Kevin, The Roman Syria and the near East, London 2003.

Цермановић-Кузмановић, Александрина, Комини - Municipium S..., некрополе, Београд 1998.

Цермановић-Кузмановић, Александрина, Велимировић-Жижић Оливера, Срејовић Драгослав, Античка Дукља, некрополе. Цетиње 1975.

Dautova-Ruševljan, Velika, Kasnoantička nekropola kod Sviloša u Sremu, Novi Sad 2003.

\footnotetext{
${ }^{48} \mathrm{Na}$ šta ukazuju slučajevi istovremenih sahrana inhumiranih i spaljenih pokojnika unutar istog grobnog mesta, ili pak upotreba istog groba za vremenski odvojene sahrane različito tretiranih pokojnika: Љ. Зотовић, Промене, 9; Љ. Зотовић, Јужне некрополе, 44; Љ. Зотовић, Ч. Јордовић, Viminacium 1, 63, G-107; S. Golubović, Sahranjivanje и Viminacijuти, 265-266; И. Микулчић, Раноримски скелетни гробови, 91-93.
} 
Davies, Jon Death, Burial and Rebirth in the Religions of Antiquity, London 1999.

Џонсон, Метју, Археолошка теорија, Београд 2009.

Faber, Andrea, Fasold, Peter, Struck, Manuela, Witteyer, Marion, Einleitung, Körpergräber des 1.-3. Jahrhunderts in der Römischen Welt. Internationales Kolloquium, Frankfurt am Main, 19.- 20, Nove4mber 20042004 (Hsg. Andrea Faber, Peter Fasold, Manuela Struck und Marion Witteyer), Archäologisches Museum Frankfurt, Frankfurt, 2007, 11-16.

Fahlander, Frederik, The Materiality of Serial Practice, a Microarchaeology of Burial, Uddevalla 2003.

Fahlander, Frederik, Oestigaard Terje, The Materiality of Death: Bodies, Burials, Beliefs, The Materiality of Death: Bodies, Burials, Beliefs (Eds. Frederik Fahlander and Terje Oestigaard), BAR International Series, Oxford 2008, 1-16.

Fidanovski, Slobodan, Nekropole municipijuma DD u svetlu novih istraživanja, Glasnik Muzeja Kosova 15-16 (1987-1988), Prišitina 1988, 11-49.

Фидановски, Слободан, Цвјетићанин Татјана, Римска вила и некропола на локалитету Каменитица- Моравиште у Малој Копашници код Грделице, Археолошка истраживања Е -75, свеска 1 (ур. Марин Брмболић), Београд 2005, 49-123.

Garašanin, Milutin, Razmatranje o nekropolama tipa Mala Kopašnica-Sase, Godišnjak VI, Centar za balkanološka ispitivanja ANU BiH 4, Sarajevo 1968, 5-35.

Gennep, Arnold van, The Rites of Passage, Death, Mourning, and Burial: A Cross-Cultural Reader (ed. Antonius C. G. M. Robben), Blackwell Publishing, Malden-Oxford 2004, 213-223.

Golubović, Snežana, Graves of the Mala Kopašnica-Sase Type at the Viminacium Cemetery from an Aspect of thir Ethnic Origin, The Thracian World at the Crossroads of Civilizations II (ed. Petre Roman), Institutul Roman de Tracologie, Bucharest 1998, 247-260.

Golubović, Snežana, Sahranjivanje u Viminacijumu od I do IV veka. Doktorska disertacija, Filozofski fakultet, Univerzitet u Beogradu, 2004.

Göricke-Lukić, Hermine, Sjeveroistočna nekropola rimske Murse, Zagreb-Osijek 2000.

Hingley, Richard, Globalizing Roman Culture: Unity, Diversity and Empire, London-New York 2005.

Huskinson, Janet, Looking for Culture, Identity and Power, Experiencing Rome: Culture, Identity and Power in the Roman Empire (ed. Janet Huskinson), London, 2000, 3-27.

Jones, Sean, The Archaeology of Ethnicity, Constructing identities in past and present, LondonNew York 1997.

Jones, Sean, Discourses of identity in the interpretation of the past, The Archaeology of Identities: a Reader (ed. Timothy Insoll), London-New York 2007, 44-58.

Jong, Lidewijde de, Becoming a Roman province: An analysis of funerary practices in Roman Syria in the context of empire, Unpublished Dissertation, Stanford University, 2007.

Јованова, Ленче, Михаилова Дафина, Скупи - Источна некропола - истражувања 1994.год., Macedoniae acta archaeologica 15 (1996-1997), Скопје 1999, 203-250.

Јовановић, Александар, Римске некрополе на територији Југославије, Београд 1984.

Jovanović, Aleksandar, Romanization and ethnic elements in burial practice in the southern part of Pannonia Inferior and Moesia Superior, Burial, Society and Context in the Roman World (Eds. John Pearce, Martin Millet and Manuela Struck), Oxbow Books, Oxford 2000, 204214.

Jovanović, Aleksandar, Prologue to the Research of Inhumation in Moesia Superior in the First to Third Centuries A.D, Гласник Српског археолошког друштва 22, Београд 2006, $23-44$.

Jovanović, Aleksandar, Inhumation in Moesia Superior in the 1st to 3rd century $A D$, Körpergräber des 1.-3. Jahrhunderts in der Römischen Welt. Internationales Kolloquium, Frankfurt am 
Main, 19.- 20, November 2004 (Hsg. Andrea Faber, Peter Fasold, Manuela Struck und Marion Witteyer), Archäologisches Museum Frankfurt, Frankfurt, 2007, 129-136.

Korać, Miomir, Golubović Snežana, Viminacium 2, Više grobalja, Beograd 2009.

Коракевик, Душанка, Состојбата на археолошките ископувања на античко Скупи, Macedoniae acta archaeologica 3, Скопје 1977, 143-180.

Laneri, Nicola, An Archaeology of Funerary Rituals, Performing Death: Social Analyses of Funerary Traditions in the Ancient Near East and Mediterrenean (ed. Nicola Laneri), Oriental Institute, University of Chicago, Chicago 2007, 1-13.

Lott, John Bert, The Neighborhoods of Augustan Rome, Cambridge 2004.

Lucy, Sam, Ethnic and Cultural Identities, The Archaeology of identity: Approaches to gender, age, status, ethnicity and religion (Margarita Díaz-Andreu, Sam Lucy, Stasa Babić and David N. Edwards), London, New York, 2005, 86-109.

Madsen, Jesper Majbom, The Romanization of the Greek elite in Achaia, Asia and Bithynia: Greek Resistance or Regional Discrepancies? http://www.pontos.dk/publications/paperspresented-orally/oral files/Mad_romanisationelite.pdf.

Marjanski-Manojlović, Mirjana, Rimska nekropola kod Beške u Sremu, Novi Sad 1987.

Микулчић, Иван, Раноримски скелетни гробови из Скупа, Старинар 24-25, Београд 1975, 89102

Millar, Fergus, The Roman Near East, 31 BC-AD 337. London-Cambridge-Mass. 1993.

Milošević, Petar, Kompleks rimskih nekropola u Sirmijumu, nastanak, geneza i kraj, doktorska disertacuja, Filozofski fakultet, Univerzitet u Beogradu, 1978.

Милошевић, Петар, Археологија и историја Сирмијума, Нови Сад 2001.

Morris, Ian, Burial and Ancient Society: the Rise of Greek City-State, Cambridge University Press, Cambridge 1987.

Morris, Ian, Death-Ritual and Social Structure in Classical Antiquity, Cambridge 1992.

Nilsson, Stutz Liv, More than Metaphor: Approaching the Human Cadaver in Archaeology, The Materiality of Death: Bodies, Burials, Beliefs (Eds. Frederik Fahlander and Terje Oestigaard), BAR International Series, Oxford 2008, 19-28.

Nock, Arthur D., Cremation and Burial in the Roman Empire, The Harvard Theological Review vol. 25 no. 4, 1932, 321-359.

Olsen, Bjørnar, Od predmeta do teksta: teorijske perspektive arheoloških istraživanja, Beograd 2002.

Parker, Pearson, Mike Mortuary Practices, Society and Ideology: an Ethnoarchaeological Study, Symbolic and Structural Archaeology (ed. Ian Hodder), Cambridge University Press, Cambridge 1982, 99-113.

Parker, Pearson, Mike The Archaeology of Death and Burial, Stroud 2003.

Perkins, Phil, Nevett, Lisa, Urbanism and Urbanization in the Roman World, Experiencing Rome, Culture, Identity and Power in the Roman Empire (ed. Janet Huskinson), London 2002, 213-244.

Pitts, Martin, Globalizing the local in Roman Britain: An anthropological approach to social change, Journal of Anthropological Archaeology vol. 27 no. 4, 2008, 493-506.

Pop-Lazić, Stefan, Nekropole rimskog Singidunuma, Singidunum 3, Beograd 2002, 39-51.

Revell, Louise, Roman Imprialism and Local Identities, Cambridge 2009.

Robb, John, Burial Treatment as Transformations of Bodily Ideology, Performing Death: Social Analyses of Funerary Traditions in the Ancient Near East and Mediterrenean (ed. Nicola Laneri), Oriental Institute, University of Chicago, Chicago 2007, 287-297.

Simić, Zoran, Rezultati zaštitnih arheoloških istraživanja na prostoru jugoistočne nekropole Singidunuma, Singidunum 1, Beograd 1997, 21-56. 
Спасић-Ђурић, Драгана, Прилози као знак порекла у једном гробу из Виминаиијума, Viminacium 15, Пожаревац 2007, 175-200.

Спасић-Ђурић, Драгана, Медаљон и други налази из гроба Г1733 из Виминаиијума, Гласник Српског археолошког друштва 23, Београд 2007, 323-340.

Срејовић, Драгослав, Римске некрополе раног Царства у Југославији, Старинар н.с. 1314/1962-1963, Београд 1965, 49-85.

Srejović, Dragoslav, Ispitivanje rimske nekropole u Sasama, Članci i gradja za kulturnu istoriju istočne Bosne VI, Tuzla 1965, 7-49.

Toynbee, Jocelyn M., Death and Burial in the Roman World, London 1971.

Wells, Peter S., The Barbarians Speak: How the Conquered Peoples Shaped Roman Europe, Princeton-Oxford 1999.

Woolf, Greg, Becoming Roman: The Origins of Provincial Civilization in Gaul, Cambridge 1998.

Зотовић, Љубица, Некрополе спаљених покојника на територији Горње Мезије, Лесковачки зборник 8, Лесковац 1968, 19-30.

Зотовић, Љубица, Промене у формама сахрањивања забележене на територији Југославије у времену од I до VI века, Лесковачки зборник 10, Лесковац 1970, 19-24.

Зотовић, Љубица, Јужне некрополе Виминацијума и погребни обреди, Viminacium 1, Пожаревац, 1986, 41-60.

Зотовић, Љубица, Јордовић Часлав, Viminacium 1, некропола Вище гробаља, Београд 1990. 


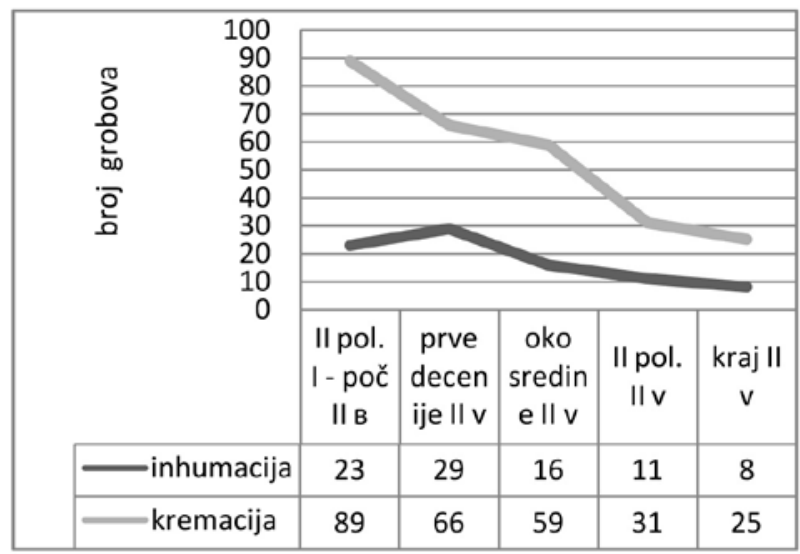

Grafikon 1: odnos broja grobova inhumiranih i kremiranih pokojnika odraslog uzrasta

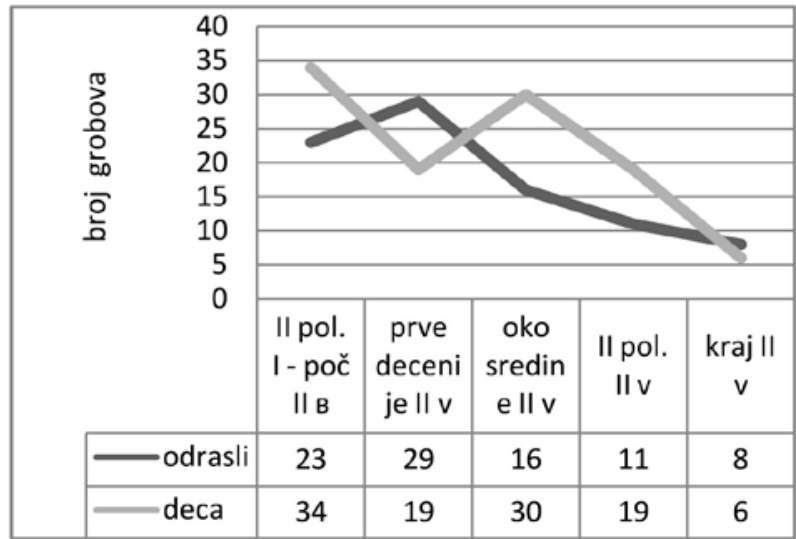

Grafikon 2: odnos broja grobova inhumiranih pokojnika odraslog i dečjeg uzrasta 


\title{
INHUMATION IN THE EARLY ROMAN PERIOD OF THE CENTRAL BALKANS: THE REFLEXION OF SOCIO-IDEOLOGICAL CHANGES?
}

\begin{abstract}
Summary
The author of the paper tried to reconsider the issue of the spread of inhumation in the area of the Central Balkans in the period of early Roman Empire. The opinion of the author was that the existing interpretations had serious deficiencies, as they relied on the culture-history archaeological paradigm. Hence, the model that dominated the Roman archaeology in the territory of former Yugoslavia presupposed that inhumation could be related to the oriental population that had migrated to the area of the Central Balkans, who practiced this treatment of a dead body and spread it within the provincial societies as a part of a general cultural influence. Another view, although lone, considered that inhumation was spread in the course of the Romanization process inspirited by newcomers from Italy and the Western provinces. Both standpoints took migrations and superior cultural influences as the main reasons behind the acceptance and eventual predominance of the inhumation. Contrary to these views, and based on the opinion that burial rites were related to the social structure, the author offered an interpretation which implied that the inhumation rite could be regarded as a means for expression of the redefined social positions that took place in the context of integration of local societies and larger, "global", Roman socio-political system. In this respect, the acceptance of the inhumation could have meant the break with some parts of the old socio-ideological system and symbolical articulation of the new social roles. This, of course, did not mean that the inhumation should be seen as a practice characteristic for particular social strata, or related exclusively to some social categories. Instead, it should be seen as one among various social strategies that had been used according to the estimated symbolic capital which could have been gained by it.
\end{abstract}

Keywords: inhumation, early-Roman period, the central Balkans, the funeral archaeology 